\title{
The Effect of Fe on Stability of Hydrogen Defects in Rutile
}

\author{
JIAQI SUN $^{1}$, YAN YANG ${ }^{1 *}$, QUNKE XIA ${ }^{1}$ \\ ${ }^{1}$ Key Laboratory of Geoscience Big Data and Deep Resource \\ of Zhejiang Province, School of Earth Sciences, Zhejiang \\ University (*Correspondence: yanyang2005@zju.edu.cn)
}

Rutile is an accessory mineral widely distributed in the metamorphic, igneous and sedimentary rocks. It can contain considerable amounts of water (tens to thousands ppm) in the form of hydrogen defects. It is not only identified as one of the important carriers of water into the mantle, but also plays crucial rules in material science since the exciting finding of increasing solar absorption for photocatalysis with hydrogenated rutile. Because of the importance of hydrogen defects, many studies have focused on hydrogen transport feature in rutile based on synthetic samples or theoretical calculations. In natural rutile, there are commonly several possible substitutions for titanium such as pentavalent $\left(\mathrm{Nb}^{5+}\right.$, $\left.\mathrm{Ta}^{5+}\right)$, trivalent $\left(\mathrm{Al}^{3+}, \mathrm{Cr}^{3+}, \mathrm{Fe}^{3+}\right)$, and divalent $\left(\mathrm{Mg}^{2+}, \mathrm{Ca}^{2+}\right)$ cations. Coupled substitutions of these cations are usually charge-balanced by incorporation of hydrogen in the rutile structure. To investigate impacts of chemical compositions on hydrogen defects in natural rutile, we carried out in situ high temperature infrared spectroscopic studies on 8 rutile samples from different localities.

The results reveal three new phenomena. (1) All the samples show two main $\mathrm{OH}$ bands around 3279 and $3297 \mathrm{~cm}^{-1}$ in the IR spectra, but with minor difference in frequencies. The Fe concentration displays a positive correlation with the frequency of the $3297 \mathrm{~cm}^{-1}$ band and negative correlation with the $3279 \mathrm{~cm}^{-1}$ band, respectively. (2) Both $\mathrm{OH}$ bands shift to lower wavenumbers with the temperature increasing, but with different amplitudes. The temperature-induced frequency shift of the $3279 \mathrm{~cm}^{-1}$ band is larger than that of the $3297 \mathrm{~cm}^{-1}$ band. Moreover, Fe concentration correlates negatively with the temperature-induced frequency shift of the $3297 \mathrm{~cm}^{-1}$ band, with little effect on the $3279 \mathrm{~cm}^{-1}$ band. (3) The variations in the absorbances of the two $\mathrm{OH}$ bands before heating and after quenching of the samples demonstrate that the water loss rate is higher for the $3279 \mathrm{~cm}^{-1}$ band than the $3297 \mathrm{~cm}^{-1}$ band, and both negatively correlates with the Fe concentration.

This study suggests that the incorporation of Fe should have stabilized hydrogen defects at elevated temperatures, providing new insights into both water transport in the deep Earth and rutile role in material science. 